\title{
Developing a simulation programme in line with the internal medicine curriculum
}

\author{
Authors: Lucy Baxter and Simon Panter
}

\section{Introduction}

South Tyneside District Hospital had an underutilised simulation facility. Patient safety initiatives, Shape of Training and the subsequent development of the internal medicine (IM) curriculum ${ }^{1}$ demonstrated that expansion of our simulation offering was necessary. The IM curriculum encourages use of simulation for training throughout the 3 years: for emergency presentations, for clinical skills and for non-technical skills.

\section{Method}

We developed three training days each mapped to the IM curriculum. In all three years of IM training, a clinical skills day covering the core procedures will be offered. South Tyneside has a number of part task trainers available for this.

In IM year 1, a simulation day covering the emergency scenarios will be offered and in IM year 2, a 'skills for registrars' day covering the non-technical skills required to be an on-call medical registrar will be offered. We developed and trialled these days with current core medical and acute care common stem-acute medicine (ACCSAM) trainees.

\section{Results}

A simulation training day for all core medical trainees across South Tyneside and Sunderland Hospitals has been developed to meet their learning outcomes for the emergency presentations in their curriculum: shocked patient, unconscious patient, cardiac arrest and anaphylaxis. The scenarios incorporate the clinical presentations and management, alongside some human factors that they may find themselves managing as medical registrars.

Sixteen core medical training doctors (years 1 and 2) attended over four sessions. Feedback was universally positive, with $94 \%$ rating the day as excellent and $6 \%$ as good. Written feedback included:

> 'Useful to be able to practise management of emergency scenarios in real time with human factors.'

> 'Human factors aspect of scenarios were really useful, I've never had that in SIM before.'

> 'I will definitely recommend to colleagues.'
A second simulation training day was developed to cover the non-technical skills required to be an on-call registrar. This took the format of a night shift where participants had to manage the acute take, clinically unwell patients, cardiac arrest, junior colleagues, handover and leadership of the team.

Three core medical and ACCS-AM trainees attended. Feedback was positive, with $100 \%$ rating the course as excellent. A second day will be offered to six further trainees. Written feedback included:

> 'I liked the theme of "a night shift" with interlinked cases/ scenarios.'

> 'I think this was probably cleverer than we realised; there was lots of hidden learning.'

> 'Really useful discussions around end of life, capacity and cardiac arrest. And we could relate it to real-life scenarios about how we could improve our practice.'

A clinical skills day is under development and will be trialled late this year.

\section{Conclusions}

This simulation programme has been well received by core medical and ACCS-AM trainees, with feedback showing that they found it useful and relevant. It is mapped to the IM curriculum in order to meet their simulation requirements and curriculum outcomes. We plan to share it regionally and to integrate it into the IM programme when it launches this year.

\section{Reference}

1 Joint Royal Colleges of Physicians Training Board. New internal medicine curriculum. London: JRCPTB, 2019. www.jrcptb.org.uk/imt [Accessed 3 April 2019]. 